\title{
Detecting climatically driven phylogenetic and morphological divergence among spruce (Picea) species worldwide
}

\author{
Guo-Hong Wang ${ }^{1, *}$, He Li ${ }^{1, *}$, Hai-Wei Zhao ${ }^{1,2}$, and Wei-Kang Zhang ${ }^{1}$ \\ ${ }^{1}$ State Key Laboratory of Vegetation and Environmental Change, Institute of Botany, Chinese Academy of Sciences, \\ Beijing 100093, China \\ ${ }^{2}$ University of the Chinese Academy of Sciences, Beijing 100049, China \\ *These authors contributed equally to this work.
}

Correspondence to: Guo-Hong Wang (ghwangaq@ibcas.ac.cn)

Received: 28 October 2016 - Discussion started: 2 November 2016

Revised: 3 March 2017 - Accepted: 8 April 2017 - Published: 5 May 2017

\begin{abstract}
This study aimed to elucidate the relationship between climate and the phylogenetic and morphological divergence of spruces (Picea) worldwide. Climatic and georeferenced data were collected from a total of 3388 sites distributed within the global domain of spruce species. A phylogenetic tree and a morphological tree for the global spruces were reconstructed based on DNA sequences and morphological characteristics. Spatial evolutionary and ecological vicariance analysis (SEEVA) was used to detect the ecological divergence among spruces. A divergence index $(D)$ with $(0,1)$ scaling was calculated for each climatic factor at each node for both trees. The annual mean values, extreme values and annual range of the climatic variables were among the major determinants for spruce divergence. The ecological divergence was significant $(P<0.001)$ for 185 of the 279 comparisons at 31 nodes in the phylogenetic tree, as well as for 196 of the 288 comparisons at 32 nodes in the morphological tree. Temperature parameters and precipitation parameters tended to be the main driving factors for the primary divergences of spruce phylogeny and morphology, respectively. Generally, the maximum $D$ of the climatic variables was smaller in the basal nodes than in the remaining nodes. Notably, the primary divergence of morphology and phylogeny among the investigated spruces tended to be driven by different selective pressures. Given the climate scenario of severe and widespread drought over land areas in the next 30-90 years, our findings shed light on the prediction of spruce distribution under future climate change.
\end{abstract}

\section{Introduction}

Environmental conditions play important roles in speciation (Mayr, 1947; Darnell and Dillon, 1970; Wiens, 2004; Givnish, 2010; Schemske, 2010; Weber et al., 2017). However, quantitative investigations of environmental influences on the origin and divergence of species are less common than expected, especially in plants (Givnish, 2010; López-Reyes et al., 2015). For example, although taxonomic and phylogenetic studies have explicitly addressed phylogenetic and morphological divergence among spruces (Farjón, 1990; Sigurgeirsson and Szmidt, 1993; Fu et al., 1999; Ran et al., 2006; Li et al., 2010; Lockwood et al., 2013), ecological differentiation among sister groups or species remains unknown. Ecological vicariance differs from geographical vicariance (Wiley, 1988; Luebert et al., 2017) and indicates the ecological differentiation among sister groups or sister species within taxa, which provides important information and ecological interpretations for the phylogenetic and morphological divergence among taxa (Escudero et al., 2009; Struwe et al., 2011).

Spruce (Picea A. Dietrich) is an important component of boreal vegetation and subalpine coniferous forests and has a wide geographical range that covers the Northern Hemisphere and extends from the Eurasian continent to North America (Farjón, 2001; Spribille and Chytry, 2002). Nearly 34 species are recognized in the genus Picea worldwide (Farjón, 2001). Although taxonomic schemes of Picea based on morphological characteristics differ slightly among authors, a consensus has been reached for the criterion to de- 
termine the first several subdivisions (Liu, 1982; Farjón, 1990; Taylor, 1993; Fu et al., 1999). Accordingly, several sections within Picea have been classified based on morphological similarity. For example, section Picea and section Casicta are characterized by quadrangular leaves and flattened leaves, respectively (Farjón, 1990). Alternatively, spruce species can be classified into phylogenetically distinct clades, namely clade 1 , a Eurasian clade; clade 2, a North American clade; and clade 3, an Asian clade with one North American species (Ran et al., 2006; Lockwood et al., 2013). These classification schemes based on chloroplast DNA (cpDNA) sequences have the potential to reveal the phylogenetic affinity among spruces. We aimed to elucidate the ecological differentiations between sister groups or species identified based on their phylogenetic affinity and morphological similarity.

A species' ecological niche depends on both the species' adaptation to its present habitat and the legacy of its ancestors (Wiens, 2004). Although species tend to retain similar ecological niches as their immediate ancestors, which is generally called phylogenetic niche conservatism (Münkemüller et al., 2015; Pyron et al., 2015), natural selection of ecologically important traits is the key process that determines the successful adaptation of incipient species (Peterson et al., 1999; Webb et al., 2002; Wiens and Graham, 2005). In addition, speciation tends to occur in geographic dimensions, whereas ecological differences evolve over time (Peterson et al., 1999). Thus, there should be a tradeoff between niche conservatism and ecological differences among splits in the phylogeny of given taxa over evolutionary timescales. Spruces likely originated in the early Tertiary or Late Cretaceous era. The fossil spruce species Picea burtonii Klymiuk et Stockey is regarded as the earliest fossil record for Picea and dates to approximately $136 \mathrm{Ma}$ (Klymiuk and Stockey, 2012). This ancestor of extant spruces dates to the Oligocene (Sigurgeirsson and Szmidt, 1993; LePage, 2001; Ran et al., 2006; Lockwood et al., 2013). The divergence times of extant spruces occurred over a long timescale, with a range of approximately 28 to $1.8 \mathrm{Myr}$ from the basal node to the terminal nodes (Lockwood et al., 2013). We hypothesize that there should be a relationship between the time since separation and the magnitude of ecological divergence or niche conservatism. Specifically, we expect to observe an increasing magnitude in terms of ecological divergence among sister groups from the basal nodes (older) to the terminal nodes (younger) on an evolutionary timescale because natural selection would favor species with high levels of ecological adaptation.

Although phylogenetically close species are likely to be similar in appearance to one another, differences in the rate of evolution may substantially obscure these similarities (Baum et al., 2005). In the genus Picea, none of the morphologybased classification schemes are congruent with or supported by the schemes derived from cpDNA-based phylogenies. Therefore, spruce species within a taxonomic section are not necessarily phylogenetically more similar than those in different sections or subsections; this indicates that parallel evolution, i.e., the repeated appearance of similar characteristics that occur among distantly related species (Went, 1971; Hoekstra and Price, 2004; Schluter et al., 2004; Orr, 2005; Bailey et al., 2015), occurs in Picea. Therefore, we hypothesize that the divergence of morphology and phylogeny among the investigated spruce species may be subject to different selective pressures under parallel evolution.

Evolutionary trees indicate historical relationships among organisms (Baum et al., 2005). This "tree-thinking" approach has been used in almost all branches of biology to detect relatedness among organisms (Baum and Offner, 2008) and to examine ecological divergence between sister clades or species (Struwe et al., 2011). In this study, tree-thinking methods were used to examine the ecological divergence among spruce species worldwide by reconstructing a phylogenetic tree and a morphological tree. A dataset of spruce species was compiled to test our hypothesis by answering the following three questions: are the climatic variables extracted from the current spruce locations correlated with the divergence among spruces? If so, is there a relationship between the time since separation and the magnitude of ecological divergence? Lastly, is the morphological and phylogenetic divergence among spruce species subject to different selective pressures?

\section{Materials and methods}

\subsection{Distribution data}

The sampling sites were selected from within the entire natural range of spruce species in the Northern Hemisphere, extending over a wide geographical range (latitude: 22.8 $69.9^{\circ} \mathrm{N}$; longitude: $53-165^{\circ} \mathrm{W}, 5-155^{\circ} \mathrm{E}$; altitude: $103-$ $4700 \mathrm{~m}$ a.s.l.) and exhibiting a steep climatic gradient, ranging from cold-temperate to subtropical zones (Fig. 1).

Included in the genus Picea are 34 species (Farjón, 2001). The global spruce checklist used in this study was primarily based on Farjón (2001) and refined according to Flora of China (Fu et al., 1999). Specifically, two species distributed in western China according to Farjón (1990), Picea retroflexa and $P$. aurantiaca, were treated as a synonym and as a variety of $P$. asperata, respectively, in Flora of China. We followed the Chinese classification. Accordingly, the checklist used for this study contained 33 spruce species.

Georeferenced data for the 33 spruce species were partially downloaded from the Global Biodiversity Information Facility (GBIF), an international open data infrastructure. Original data in the GBIF are derived from various sources, such as natural history explorations (specimens or records) collected over the past 300 years, current observations and automated monitoring programs (GBIF, 2015). We carefully verified the original data downloaded from GBIF by excluding those data points with geolocations outside of the 

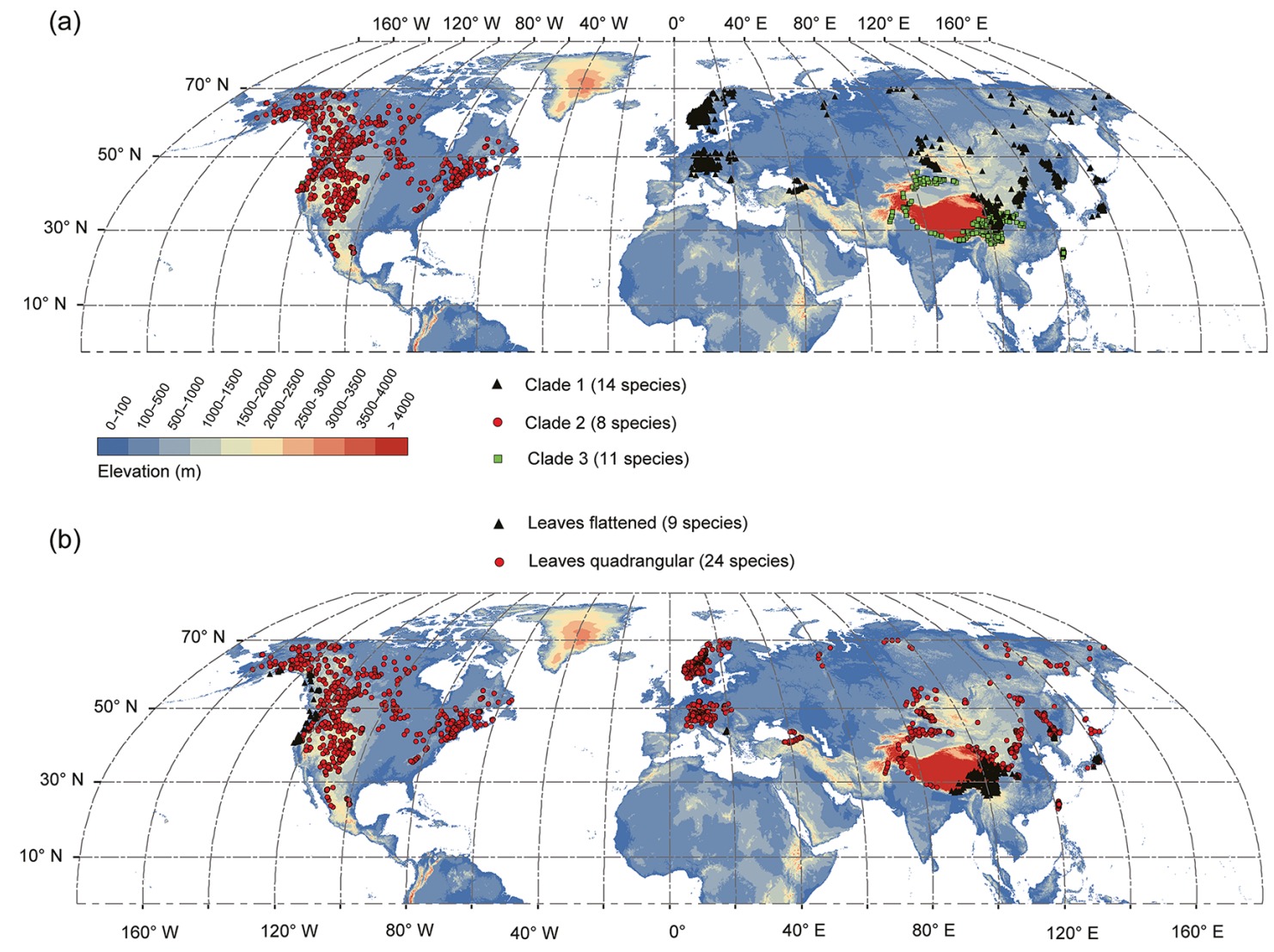

Figure 1. Sites were sampled across the entire range of spruces worldwide. Sites marked with different symbols represent three phylogenetically distinct clades (a) and two morphological groups (b). Elevation gradients are indicated by colored fields.

natural distribution ranges (either horizontally, vertically or both). As a result, 2397 point locations from the GBIF remained after the verification, and they primarily represented spruce species in North America, Europe and eastern Asia (Japan and the Korean Peninsula). Additional data for the spruce species from mainland China and Taiwan (991 locations for 16 species) were obtained from georeferenced herbarium collection records (490 sites) (Li et al., 2016) from the herbarium of the Institute of Botany, Chinese Academy of Sciences; recent fieldwork (370 sites, unpublished); and published sources (41 sites) (Tseng, 1991; Yang et al., 2002). As a result, 3388 point locations for the 33 spruce species were available for this analysis.

\subsection{Climatic variables}

A total of 19 climatic variables (Table 1) with a resolution of approximately $1 \mathrm{~km}^{2}$ for the 3388 point locations were acquired and downloaded from WorldClim v1.4 (http: //www.worldclim.org) (Hijmans et al., 2005). The values of each climate variable at each site were extracted using the software QGIS (http://www.qgis.org), and the final data were exported to an Excel worksheet for subsequent analysis.

\subsection{Data analysis}

DNA sequences were retrieved from the NCBI GenBank (www.ncbi.nlm.nih.gov) to reconstruct a phylogenetic tree of the 33 spruce species (Fig. 2). This phylogenetic tree was constructed based on three plastid (trnL-trnF, trn-psbA and trnS-trnG) and two mitochondrial (nad5 intron 1 and nad1 intron 2) DNA sequences, and it was equivalent to that of Lockwood et al. (2013), who proposed an improved phylogeny of Picea. In addition, we reconstructed a morphological tree of the 33 spruce species (Fig. 3) based on Farjón (1990), Taylor (1993) and Fu et al. (1999). The first several splits in the tree primarily revealed divergence in the shape of the leaf cross section, the position of the stomatal line on the leaf surface, and the texture and arrangement of the seed scale, whereas traits such as the size of the leaf, seed cone and seed scale, and the hairiness of the leaf or twig are important indicators for subsequent splits in the trees. The morphological tree and the phylogenetic tree contained 32 and 31 nodes, respectively.

To detect ecological divergence among sister groups or species in the abovementioned trees, we used spatial evolutionary and ecological vicariance analysis (SEEVA; Struwe et al., 2011), which can incorporate climatic data with phylo- 


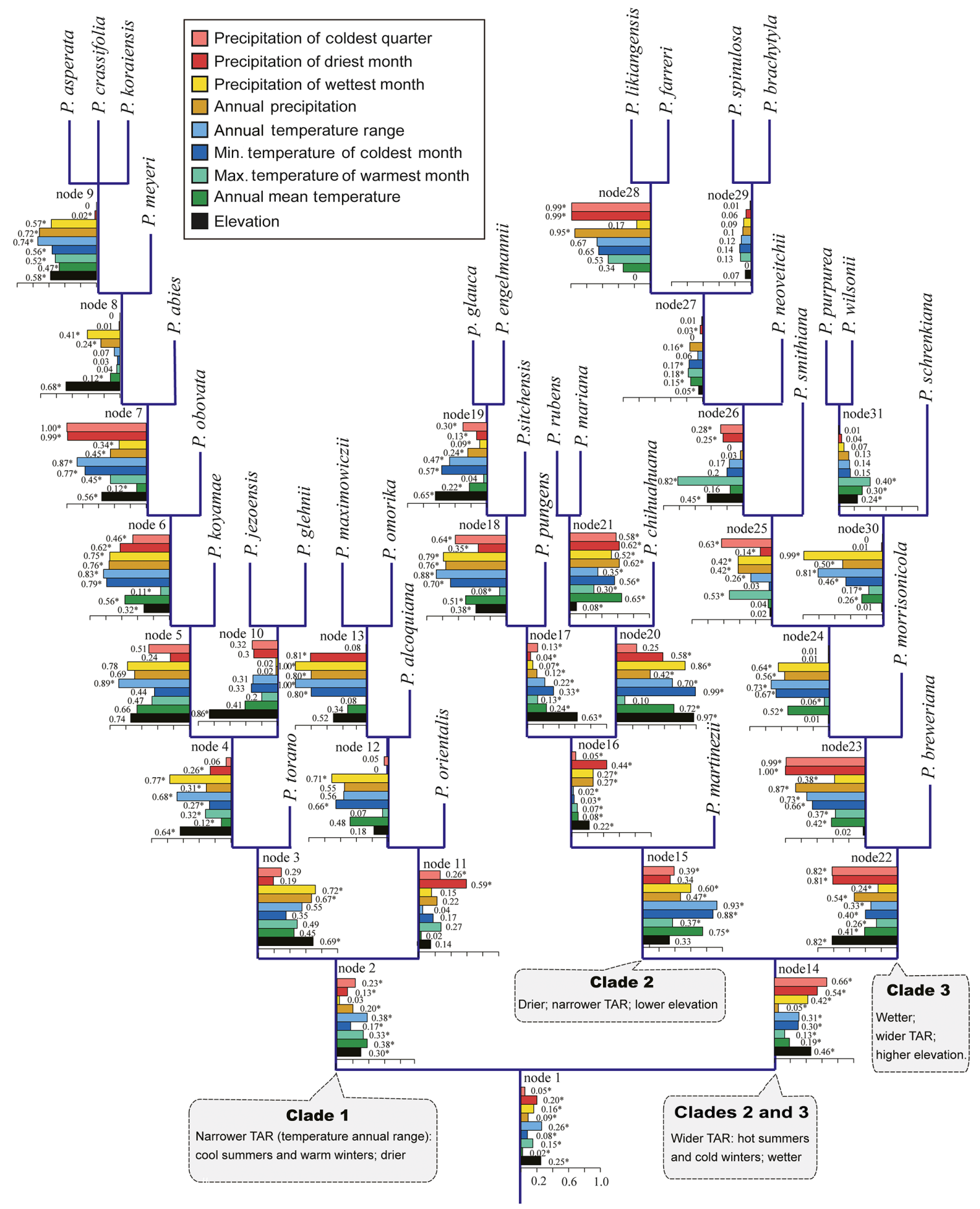

Figure 2. Divergence indices (scales range from 0 to 1) shown as histograms for elevation and for the eight climatic variables for each node of the phylogeny of Picea worldwide. * Indicates a significant difference in ecological features after Bonferroni correction $(P<0.0016)$. 


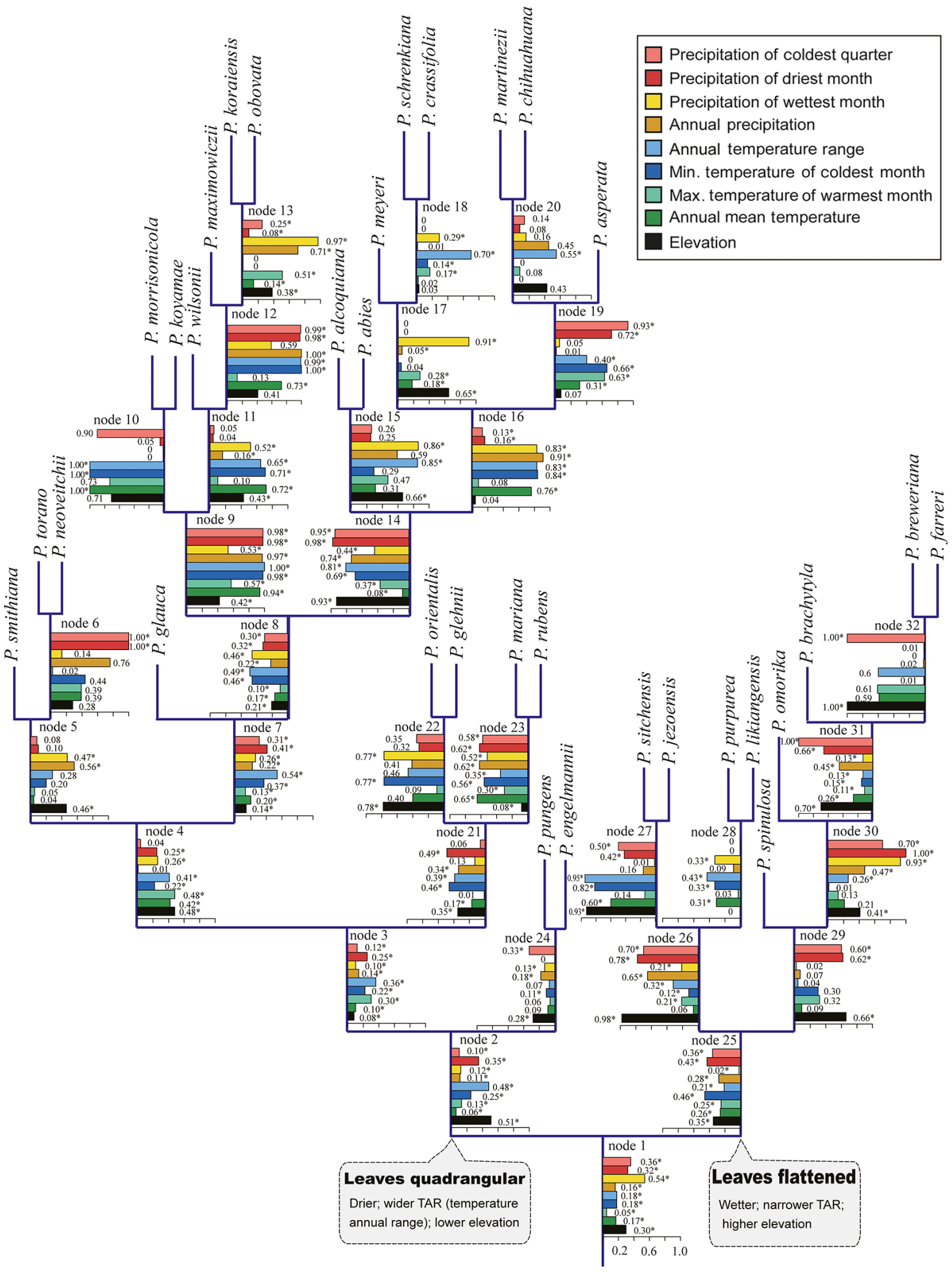

Figure 3. Divergence indices (scales range from 0 to 1) shown as histograms for elevation and for the eight climatic variables for each node of the morphology of Picea worldwide. * Indicates a significant difference in ecological features after Bonferroni correction $(P<0.0016)$. 
Table 1. Factor analysis showing the eigenvalues, variance percentages, cumulative percentages and correlations of 19 climatic variables with the five components. Climatic variables in bold were selected for further analysis.

\begin{tabular}{lrrrrr}
\hline Climatic variables & \multicolumn{3}{c}{ Components } \\
\cline { 2 - 6 } & 1 & 2 & 3 & 4 & 5 \\
\hline Eigenvalues & 8.27 & 3.60 & 2.51 & 2.26 & 1.24 \\
Variance \% & 43.52 & 18.93 & 13.21 & 11.89 & 6.51 \\
Cumulative \% & 43.52 & 62.46 & 75.67 & 87.55 & 94.06 \\
\hline Annual mean temperature (AMT) & $\mathbf{0 . 8 0 3}$ & 0.222 & 0.082 & 0.513 & -0.152 \\
Mean diurnal range (MDR) & -0.118 & -0.155 & -0.686 & 0.476 & 0.31 \\
Isothermality (I) & 0.687 & 0.283 & -0.45 & 0.158 & 0.307 \\
Temperature seasonality (TS) & -0.928 & -0.237 & -0.099 & 0.204 & -0.12 \\
Max. temperature of warmest month (MTWM) & 0.037 & -0.155 & -0.129 & $\mathbf{0 . 9 6 8}$ & 0.01 \\
Min. temperature of coldest month (MTCM) & $\mathbf{0 . 9 3 1}$ & 0.216 & 0.257 & 0.086 & 0.006 \\
Temperature annual range (TAR) & $-\mathbf{0 . 8 5 4}$ & -0.267 & -0.294 & 0.329 & -0.001 \\
Mean temperature of wettest quarter (MTWeQ) & -0.123 & 0.091 & -0.066 & 0.48 & -0.788 \\
Mean temperature of driest quarter (MTDQ) & 0.841 & 0.093 & 0.138 & 0.116 & 0.408 \\
Mean temperature of warmest quarter (MTWaQ) & 0.14 & 0.02 & 0.04 & 0.918 & -0.294 \\
Mean temperature of coldest quarter (MTCQ) & 0.946 & 0.24 & 0.108 & 0.179 & 0.007 \\
Annual precipitation (AP) & 0.306 & $\mathbf{0 . 8 5 6}$ & 0.365 & -0.041 & 0.178 \\
Precipitation of wettest month (PWM) & 0.288 & $\mathbf{0 . 9 4 2}$ & -0.006 & -0.033 & 0.109 \\
Precipitation of driest month (PDM) & 0.147 & 0.255 & $\mathbf{0 . 9 1 1}$ & 0.008 & 0.087 \\
Precipitation seasonality (PS) & -0.109 & 0.255 & -0.887 & -0.006 & -0.131 \\
Precipitation of wettest quarter (PWeQ) & 0.297 & 0.937 & 0.026 & -0.038 & 0.134 \\
Precipitation of driest quarter (PDQ) & 0.175 & 0.302 & 0.894 & -0.003 & 0.152 \\
Precipitation of warmest quarter (PWaQ) & 0.144 & 0.888 & 0.086 & -0.057 & -0.313 \\
Precipitation of coldest quarter (PCQ) & 0.323 & 0.402 & 0.418 & -0.016 & $\mathbf{0 . 6 5 2}$ \\
\hline
\end{tabular}

genetic data and morphological data using statistical methods to investigate ecological vicariance in speciation. The SEEVA compares the differences between each of the climatic variables for each node. A divergence index $(D)$ with $(0,1)$ scaling was calculated for each climatic factor at each node. $D=0$ indicates no difference between sister clades or groups, whereas $D=1$ indicates a maximum difference. Fisher's exact test (Fisher, 1958), which generally provides a better $P$ value for tests with small sample sizes, was performed to determine the significance of $D$. Because 31 and 32 independent tests were conducted for each of the climatic variables, a $P$ value less than 0.0016 indicated a significant difference in the ecological features for splits at a given node after performing a Bonferroni correction, i.e., $\alpha=0.05 /(31$ or 32$) \approx 0.0016$. Details on the calculations are available in Struwe et al. (2011). The SEEVA software can be downloaded from http://seeva.heiberg.se.

A factor analysis was conducted to eliminate the redundant climatic variables, and a principal component analysis (PCA) of the climatic variables was performed using the SPSS statistical package (SPSS, Chicago, IL, USA). In addition, we ran the SEEVA by taking all the 16 climate factors into account. To illustrate the results briefly and clearly, we focused on how the mean value and extreme values of climate factors could influence spruce divergence. The selected climatic variables must have both higher divergence indices for the first split on the phylogenetic tree and the morphological tree and relatively higher loading on the five component axes. As a result, we mapped eight climate factors in the histograms, including four temperature variables (annual mean temperature, AMT; minimum temperature of the coldest month, MTCM; maximum temperature of the warmest month, MTWM; and temperature annual range, TAR) and four precipitation variables (annual precipitation, AP; precipitation of the wettest month, PWM; precipitation of the driest month, PDM; and precipitation of the coldest quarter, PCQ). In addition, elevation as a spatial variable was also used to detect the ecological vicariance among sister groups because spruce is an elevation-sensitive taxon (Farjón, 1990; Taylor, 1993; Fu et al., 1999).

We compared the means of the nine abiotic variables among sister groups at several key splits (i.e., the first two split levels) of both trees using ANOVA to further interpret the observed ecological divergence.

\section{Results}

\subsection{Variation in climatic variables}

A factor analysis of the climatic variables across sampling sites revealed five dominant climatic gradients that accounted for $94.06 \%$ of the variance (Table 1). The first component, 
which had an eigenvalue of 8.27 and accounted for $43.52 \%$ of the variance, was a gradient characterized by variation in temperature variables. The second component, which had an eigenvalue of 3.60 and accounted for $18.93 \%$ of the variance, was a gradient characterized by variation in precipitation variables. The third, fourth and fifth components, which accounted for $13.21,11.89$ and $6.51 \%$ of the variance, respectively, were characterized by variation in the precipitation of the driest month or quarter and precipitation seasonality; maximum temperature of the warmest month or quarter; and mean temperature of the wettest quarter and precipitation of the coldest quarter, respectively.

\subsection{Ecological divergence among sister groups or species in the phylogeny of Picea}

Ecological divergence as indicated by the $(0,1)$ scaled index of $D$ was significant $(P<0.0016$, significance indicated as * where relevant) for 185 of the 279 comparisons at 31 nodes in the phylogeny of Picea (see Table S1 in the Supplement). The first split, which yielded node 2 (clade 1) and node 14 (clade 2 and clade 3), was significant for all nine environmental variables. The annual temperature range $\left(D=0.26^{*}\right)$ showed higher divergence, and it was followed by elevation $\left(D=0.25^{*}\right)$ and precipitation of the driest month $\left(D=0.20^{*}\right)$. The spruce species in clade 1 tended to occur in climates with a lower annual temperature range and lower precipitation compared with the spruce species in node 14 . The divergence within node 14 and between node 15 (clade 2) and node 22 (clade 3) was also significant for all nine environmental variables. The parameters precipitation of the coldest quarter, precipitation of the driest month and precipitation of the wettest month had relatively high divergence $\left(D=0.66^{*}\right.$ to $\left.0.42^{*}\right)$. Elevation exhibited substantial divergence $\left(D=0.46^{*}\right)$, whereas the temperature variables showed lower divergence $\left(D=0.13^{*}\right.$ to $\left.0.31^{*}\right)$. Compared with clade 3 , clade 2 occurred in climates with lower precipitation levels and a higher annual temperature range. Node 2 represented a split within clade 1 (the Eurasian clade) between a subclade at a higher elevational zone (in the Caucasian area and Japan) with a warmer and wetter climate and a subclade at a lower elevational zone (especially in the boreal area) with a cold and dry climate. The elevation and temperature features showed relatively higher divergence ( $D=0.17^{*}$ to $0.38^{*}$ ) compared with the precipitation variables $\left(D=0.03^{*}\right.$ to $\left.0.23^{*}\right)$ (Fig. 2, Table 2).

The ecological divergence for the subsequent 28 splits in the phylogeny of Picea, i.e., from node 3 to node 13 and from node 15 to node 31 , was significant for approximately $63 \%$ of the comparisons. However, a universal pattern was not observed in terms of the ecological divergence for the remaining splits, which varied according to the sister groups or species. This finding suggests that a particular combination of environmental features is important for particular splits among sister groups or species (Fig. 2, Table 2).

\subsection{Ecological divergence among sister groups or species in the morphology of Picea}

Ecological divergence was significant $(P<0.0016$, indicated as * where relevant) for 196 of the 288 comparisons at 32 nodes in the morphological tree of Picea (see Table S2 in the Supplement). Of the 32 nodes, we focused on three splits that represent several key morphological divergences in Picea. Specifically, the split of node 1 represents divergence in the shape of the leaf cross section and the position of the stomatal line on the leaf surface, whereas the split of node 2 and node 25 represents divergence in the texture and seed scale arrangement. The remaining 29 splits, i.e., from node 3 to node 24 and from node 26 to node 32 , reflect divergence in the leaf size, seed cone size, hairiness (pubescent vs. glabrous), and branchlet color, and these differences were significant for approximately $65 \%$ of the comparisons $(P<0.0016$, Fig. 3$)$.

The first split of the morphology-defined topology tree (Fig. 3) yielded node 2 (leaf quadrangular) and node 25 (leaf flattened) and was significant for all nine environmental variables $(P<0.0016)$. Precipitation features $(D=$ $\left.0.16^{*}-0.54^{*}\right)$, predominantly precipitation of the wettest month, showed much stronger divergence compared with that of temperature features $\left(D=0.05^{*}-0.18^{*}\right)$, with elevation showing a moderate divergence $\left(D=0.30^{*}\right)$. Spruce species with quadrangular leaves tended to be favored by drier habitats with higher temperature annual ranges in lower elevational zones, which is inconsistent with the habitats for spruces with flattened leaves (Table 2). Such an overall pattern, however, does not necessarily hold true for the sister groups or species that present different leaf cross sections (flattened vs. quadrangular) but close phylogenetic relationships. Sister groups or species at node 10, node 13, node 18, node 26 and node 31 in the phylogenetic tree are relevant examples (Fig. 3). For example, although elevation was important for the divergence between $P$. jezoensis and $P$. glehnii (node 10), temperature parameters were important for the divergence between $P$. wilsonii and $P$. purpurea (node 31 ).

The second-level splits in the morphological tree (Fig. 3) yielded two pairs of sister groups, namely node 3 vs. node 24 (within node 2) and node 26 vs. node 29 (within node 25 ). These two pairs of spruce sister groups collectively indicated divergence in the seed scale characteristics, i.e., closely arranged seed scales with a rigid woody texture vs. loosely arranged seed scales with a thin, flexible, leathery or papery texture. For the split within node 2, elevation showed the highest divergence $\left(D=0.51^{*}\right)$ and was followed by annual temperature range $\left(D=0.48^{*}\right)$ and precipitation of the driest month $\left(D=0.35^{*}\right)$, whereas the remaining climatic variables had significant but relatively low divergence $\left(D=0.06^{*}-0.25^{*}\right)$. Compared with the results for node 24 (loosely arranged seed scales), the species in node 3 (closely arranged seed scales) tended to occur in lower elevational zones with higher precipitation of the driest month and a 
Table 2. Mean comparisons of the elevation and eight climatic variables (mean $\pm \mathrm{SD}$, abbreviations are the same as in Table 1) between sister groups at the first two split levels of both the phylogenetic tree and the morphological tree. Mean \pm SD values marked with different letters indicate a significant difference at $P<0.05$, and the same letter indicates a non-significant difference $(P>0.05)$.

\begin{tabular}{|c|c|c|c|c|c|c|c|c|c|c|}
\hline & $N$ & Elevation (m) & $\operatorname{AMT}\left({ }^{\circ}\right)$ & $\operatorname{MTWM}\left({ }^{\circ}\right)$ & $\operatorname{MTCM}\left({ }^{\circ}\right)$ & $\operatorname{TAR}\left({ }^{\circ}\right)$ & $\mathrm{AP}(\mathrm{mm})$ & PWM (mm) & PDM (mm) & PCQ $(\mathrm{mm})$ \\
\hline \multicolumn{11}{|c|}{ Phylogeny nodes } \\
\hline \multicolumn{11}{|c|}{ Sister groups: node 2 (clade 1 ) vs. node 14 (clade $2+$ clade 3 ) } \\
\hline 2 & 1568 & $964 \pm 750^{\mathrm{a}}$ & $3.2 \pm 4.2^{\mathrm{a}}$ & $19.6 \pm 3.7^{\mathrm{a}}$ & $-12.6 \pm 8.6^{\mathrm{a}}$ & $32.1 \pm 9.5^{\mathrm{a}}$ & $845.8 \pm 416.9^{\mathrm{a}}$ & $117.1 \pm 52.3^{\mathrm{a}}$ & $38.0 \pm 25.7^{\mathrm{a}}$ & $158.9 \pm 124.2^{\mathrm{a}}$ \\
\hline 14 & 1820 & $1721 \pm 1150^{\mathrm{b}}$ & $3.8 \pm 5.0^{\mathrm{b}}$ & $21.8 \pm 3.9^{\mathrm{b}}$ & $-13.9 \pm 8.8^{\mathrm{b}}$ & $35.7 \pm 8.8^{\mathrm{b}}$ & $910.7 \pm 727.6^{\mathrm{b}}$ & $143.6 \pm 119.0^{\mathrm{b}}$ & $26.9 \pm 27.8^{\mathrm{b}}$ & $186.5 \pm 209.3^{\mathrm{b}}$ \\
\hline \multicolumn{11}{|c|}{ Sister groups: node 15 (clade 2) vs. node 22 (clade 3 ) } \\
\hline 15 & 1100 & $1176 \pm 906^{\mathrm{a}}$ & $2.5 \pm 5.0^{\mathrm{a}}$ & $22.5 \pm 3.6^{\mathrm{a}}$ & $-16.6 \pm 8.2^{\mathrm{a}}$ & $39.1 \pm 7.3^{\mathrm{a}}$ & $784.1 \pm 442.6^{\mathrm{a}}$ & $106.3 \pm 61.6^{\mathrm{a}}$ & $35.7 \pm 27.7^{\mathrm{a}}$ & $190.7 \pm 180.0^{\mathrm{a}}$ \\
\hline 22 & 720 & $2554 \pm 971^{\mathrm{b}}$ & $5.9 \pm 4.3^{\mathrm{b}}$ & $20.6 \pm 4.0^{\mathrm{b}}$ & $-9.9 \pm 8.1^{\mathrm{b}}$ & $30.6 \pm 8.4^{\mathrm{b}}$ & $1104.0 \pm 989.0^{\mathrm{b}}$ & $200.8 \pm 157.0^{\mathrm{b}}$ & $13.5 \pm 21.8^{\mathrm{b}}$ & $180.0 \pm 247.4^{\mathrm{a}}$ \\
\hline \multicolumn{11}{|c|}{ Sister groups: node 3 vs. node 11 (two sister groups within clade 2) } \\
\hline 3 & 1502 & $951 \pm 755^{\mathrm{a}}$ & $3.0 \pm 4.2^{\mathrm{a}}$ & $19.4 \pm 3.6^{\mathrm{a}}$ & $-12.8 \pm 8.6^{\mathrm{a}}$ & $32.2 \pm 9.7^{\mathrm{a}}$ & $834.5 \pm 411.2^{\mathrm{a}}$ & $116.2 \pm 51.3^{\mathrm{a}}$ & $37.4 \pm 25.8^{\mathrm{a}}$ & $157.2 \pm 126.0^{\mathrm{a}}$ \\
\hline 11 & 66 & $1275 \pm 542^{b}$ & $7.1 \pm 2.8^{\mathrm{b}}$ & $22.9 \pm 2.6^{\mathrm{b}}$ & $-7.5 \pm 3.7^{\mathrm{b}}$ & $30.4 \pm 2.8^{\mathrm{b}}$ & $1101.8 \pm 464.7^{b}$ & $137.8 \pm 70.0^{\mathrm{a}}$ & $52.3 \pm 16.7^{\mathrm{b}}$ & $196.3 \pm 63.3^{b}$ \\
\hline \multicolumn{11}{|c|}{ Morphology nodes } \\
\hline \multicolumn{11}{|c|}{ Sister groups: node 2 vs. node 25 (i.e., quadrangular leaf group vs. flattened leaf group) } \\
\hline 2 & 2857 & $1191 \pm 915^{\mathrm{a}}$ & $3.1 \pm 4.7^{\mathrm{a}}$ & $20.8 \pm 4.0^{\mathrm{a}}$ & $-14.0 \pm 8.8^{\mathrm{a}}$ & $34.8 \pm 9.7^{\mathrm{a}}$ & $849.4 \pm 624.2^{\mathrm{a}}$ & $120.0 \pm 95.2^{\mathrm{a}}$ & $35.3 \pm 27.2^{\mathrm{a}}$ & $163.8 \pm 146.4^{\mathrm{a}}$ \\
\hline 25 & 531 & $2337 \pm 1222^{b}$ & $5.8 \pm 3.7^{\mathrm{b}}$ & $20.7 \pm 3.7^{\mathrm{a}}$ & $-9.3 \pm 6.6^{\mathrm{b}}$ & $29.9 \pm 5.5^{\mathrm{b}}$ & $1048.5 \pm 452.1^{\mathrm{b}}$ & $192.2 \pm 67.9^{\mathrm{b}}$ & $14.5 \pm 21.0^{\mathrm{b}}$ & $226.8 \pm 279.7^{b}$ \\
\hline \multicolumn{11}{|c|}{ Sister groups: node 3 vs. node 24 (i.e., within quadrangular leaf group: closely arranged seed scale group vs. loosely arranged group) } \\
\hline 3 & 2530 & $1059 \pm 850^{\mathrm{a}}$ & $3.0 \pm 4.8^{\mathrm{a}}$ & $20.5 \pm 3.9^{\mathrm{a}}$ & $-14.3 \pm 9.2^{\mathrm{a}}$ & $34.8 \pm 10.2^{\mathrm{a}}$ & $864.7 \pm 646.3^{\mathrm{a}}$ & $121.6 \pm 97.8^{\mathrm{a}}$ & $36.6 \pm 28.4^{\mathrm{a}}$ & $155.8 \pm 135.1^{\mathrm{a}}$ \\
\hline 24 & 327 & $2219 \pm 729^{b}$ & $3.7 \pm 3.7^{\mathrm{b}}$ & $22.8 \pm 4.0^{\mathrm{b}}$ & $-12.1 \pm 4.8^{\mathrm{b}}$ & $34.8 \pm 4.2^{\mathrm{a}}$ & $730.9 \pm 396.0^{\mathrm{b}}$ & $107.7 \pm 70.6^{\mathrm{b}}$ & $25.7 \pm 10.8^{b}$ & $225.9 \pm 204.9^{b}$ \\
\hline \multicolumn{11}{|c|}{ Sister groups: node 26 vs. node 29 (i.e., within flattened leaf group: closely arranged seed scale group vs. loosely arranged group) } \\
\hline 26 & 283 & $2806 \pm 1301^{\mathrm{a}}$ & $4.6 \pm 4.1^{\mathrm{a}}$ & $19.0 \pm 3.3^{\mathrm{a}}$ & $-12.4 \pm 7.3^{\mathrm{a}}$ & $31.4 \pm 6.7^{\mathrm{a}}$ & $996.1 \pm 564.2^{\mathrm{a}}$ & $190.1 \pm 77.4^{\mathrm{a}}$ & $15.1 \pm 23.7^{\mathrm{a}}$ & $125.5 \pm 252.6^{\mathrm{a}}$ \\
\hline 29 & 248 & $1802 \pm 854^{\mathrm{b}}$ & $7.2 \pm 2.5^{\mathrm{b}}$ & $22.5 \pm 3.2^{b}$ & $-5.7 \pm 3.0^{\mathrm{b}}$ & $28.2 \pm 2.9^{\mathrm{b}}$ & $1108.4 \pm 261.7^{b}$ & $194.6 \pm 55.3^{\mathrm{a}}$ & $13.8 \pm 17.4^{\mathrm{a}}$ & $342.4 \pm 264.2^{b}$ \\
\hline 4 & 2118 & $1124 \pm 890^{\mathrm{a}}$ & $3.0 \pm 4.9^{\mathrm{a}}$ & $20.0 \pm 3.9^{\mathrm{a}}$ & $-13.8 \pm 9.5^{\mathrm{a}}$ & $33.8 \pm 10.5^{\mathrm{a}}$ & $853.8 \pm 682.2^{\mathrm{a}}$ & $124.6 \pm 105.6^{\mathrm{a}}$ & $33.3 \pm 26.2^{\mathrm{a}}$ & $149.0 \pm 139.0^{\mathrm{a}}$ \\
\hline 21 & 412 & $724 \pm 487^{\mathrm{b}}$ & $3.2 \pm 4.3^{\mathrm{a}}$ & $23.2 \pm 2.9^{\mathrm{b}}$ & $-17.0 \pm 6.9^{\mathrm{b}}$ & $40.1 \pm 6.0^{\mathrm{b}}$ & $921.0 \pm 412.3^{\mathrm{a}}$ & $106.2 \pm 33.1^{\mathrm{b}}$ & $53.2 \pm 33.0^{\mathrm{b}}$ & $190.8 \pm 105.7^{\mathrm{b}}$ \\
\hline
\end{tabular}

wider variation of annual temperature range (Table 2). For the split within node 25 , both the minimum temperature of the coldest month $\left(D=0.46^{*}\right)$ and precipitation of the driest month $\left(D=0.43^{*}\right)$ showed substantial divergence, with a moderate divergence for elevation $\left(D=0.35^{*}\right)$. Compared with the results for node 26 (loosely arranged seed scales), the species in node 29 (closely arranged seed scales) tended to occur in lower elevational zones with higher temperature and greater precipitation in the coldest quarter (Table 2).

\subsection{Magnitude of ecological divergence and time since separation}

Nine levels of splits occurred in the phylogenetic tree. From level 1 to 3 , the $(0,1)$ scaled index of divergence $(D)$ tended to increase in terms of the median value, maximum value and interquartile range. From level 3 to 9, the maximum value of $D$ for most cases (except for level 8) was approximately 1 , whereas the median and the interquartile range were less structured (Fig. 4a). There were 10 levels of splits in the morphological tree. The maximum value of $D$, which was even slightly higher for level $1(D=0.54)$ than level 2 ( $D=0.48)$, was approximately 1 for the remaining levels. The median tended to increase from level 1 to 7 and then de- crease from level 7 to 10 . The interquartile range tended to increase from level 1 to 9 (Fig. 4b).

\section{Discussions}

\subsection{Climatic data extracted from current spruce locations capture the ecological divergence among spruces}

In this study, we used climatic data extracted from the current locations of spruce populations to examine the ecological divergence among spruce species at various timescales from approximately 28 to $1.8 \mathrm{Myr}$. Our results showed significant divergence for the ecological niches among sister groups throughout the phylogenetic tree and the morphological tree, which indicated the overall relevance of the climatic data on spruce ecological divergence at various timescales. However, the magnitude of ecological divergence (as indicated by the divergence index, $D$ ) decreased with the time since the separation of species and became much more specific, i.e., variation of $D$ among the nine environmental variables was larger in the more recent splits than in the basal splits. 
(a) Phylogenetic tree of Picea

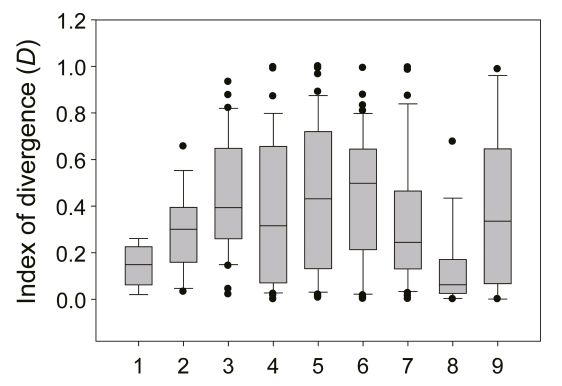

(b) Morphological tree of Picea

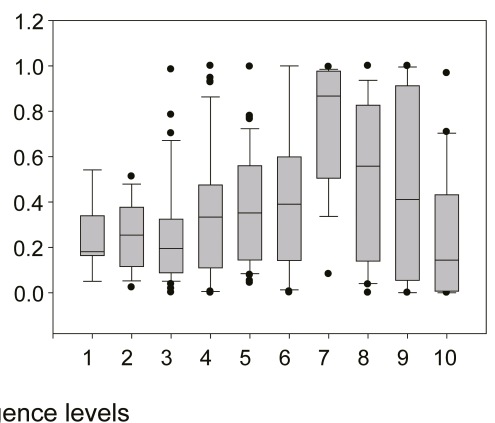

Figure 4. Box plots showing the index of divergence at each of the splitting levels in the phylogenetic tree (a) and the morphological tree (b) of spruce species worldwide. The central box in each box plot indicates the interquartile range and median, whereas the whiskers show the 10th and 90th percentiles. Mean values marked with different letters indicate a significant difference at $P<0.01$.

This finding is likely associated with the incompatibility of the timescale between environmental data and ecological divergence because the environmental data extracted from the current locations tended to be more relevant to the divergence of younger nodes than older nodes. The low ecological divergence observed at the first split in both trees, on the one hand, should be an indicator of high ecological niche conservatism (Struwe et al., 2011); on the other hand, it is likely related to the strong species interactions that obscure the splits. However, the higher divergence observed for the younger sister groups or sister species might suggest a strong selective effect of climate on extant spruce species derived from more recent splits and might also be associated with the fact that the smaller number of species of the sister groups within each node in the more recent splits have lesscomplicated trait compositions and hence weak interactions. Our first hypothesis, i.e., an increasing magnitude in terms of ecological divergence among sister groups from the basal nodes (older) to the terminal nodes (younger) on evolutionary timescales is largely verified by the findings of our study and those of a previous case study (Struwe et al., 2011).

Exceptions to the abovementioned trend were observed for a few sister groups or species in the phylogenetic tree. Specifically, within clade 3 , significant ecological divergence was not detected for the split (node 29 in Fig. 2) between $P$. spinulosa and $P$. brachytyla. These two sister species are distributed on the Tibetan Plateau and their geographical ranges are adjacent. $P$. spinulosa is distributed in the Himalayas region and has a narrow range (southern Xizang, Bhutan, Nepal and Sikkim), whereas $P$. brachytyla is distributed on the SE to E Tibetan Plateau and has a wide range. These differences suggest that instead of ecological divergence, geographical isolation caused by the deep valleys and high mountain peaks in this area, which act as barriers to gene flow between species, might have played a major role in the speciation of these two sister species ( $\mathrm{Li}$ et al., 2010). In addition, we cannot rule out the possibility that the selected climate pa- rameters as well as their relatively coarse resolution (about $1 \mathrm{~km}$ ) do not adequately describe the climatic determinants of spruce distributions.

In mountainous regions, $1 \mathrm{~km}$ of distance may cover an elevation interval of hundreds of meters and therefore introduce several degrees of difference in temperature, which may give rise to some uncertainties in the context of the detection of some subtle variations such as within-species variation or variation among elevation-sensitive species. In this case, as shown in Fig. 1a, b, instead of an elevation gradient, the geographical distributions, of the three phylogenetic clades and of the morphological groups (quadrangular leaves versus flattened leaves), are largely determined by horizontal gradients (latitude and longitude). Thus, although the resolution $(1 \mathrm{~km})$ of the climate data that we used in this study should be robust to interpret this large-scale pattern, further studies that focus on the driving force underlying the variation within species or among elevation-sensitive species should use high-resolution climate data.

\subsection{Temperature features tend to be the main driving factors of the primary divergence of spruce phylogeny}

Of the 31 splits in the phylogenetic tree of Picea, the first split is much more important than the subsequent splits because it represents the "primary trigger" that led to the divergence of the genus. Temperature parameters showed higher divergence for the first split of the spruce phylogeny, although moisture factors were not negligible. The first split of the spruce phylogeny occurred at approximately $28 \mathrm{Ma}$ in a period with severe oscillations of global temperature, which sharply declined at the end of the Eocene and then warmed during the late Oligocene and early Miocene (Lockwood et al., 2013). This oscillation may provide an explanation for the higher divergence of temperature features. The divergence among the nine environmental variables for the sub- 
sequent splits, however, varied according to the sister groups or species.

It is well established that the variations in the historical climate associated with the advancement and retreat of ice sheets during the late Tertiary and Quaternary periods played an important role in determining plant distributions (Walker, 1986; Hewitt, 2000). In this process, old taxa became extinct or survived in refugia, whereas derived taxa dispersed to new locations and underwent severe selection by climate (Hewitt, 2000; Hampe and Petit, 2010). Therefore, the formation of biogeographical plant patterns is a product of interactions among these processes (Wolf et al., 2001).

In fact, considerable variations in geology and climate have occurred since spruce originated in the late Oligocene. For example, the earliest spruce pollen fossil is from the late Oligocene to the early Miocene in Asia and was found on the Tibetan Plateau (Wu et al., 2007). Spruce pollen has frequently been found in sediments originating from the late Pliocene and the Pleistocene in northern, eastern and southwestern China (Xu et al., 1973, 1980; Shi, 1996) and Taiwan (Tsukada, 1966). A higher proportion of spruce pollen in specific sediments is generally assumed to indicate a cold period, whereas a lower proportion of spruce pollen indicates a warmer period (Xu et al., 1980). The proportion of spruce pollen in the sediments varied substantially with the geological age of the sediments, suggesting that spruce underwent frequent expansion and retreat during glacial cycles. In North America, fossils of Brewer spruce (P. breveriana) have been observed in northeastern Oregon in Miocene deposits that date to more than $15 \mathrm{Ma}$ years ago; however, the present distribution of Brewer spruce is different from the distribution of the fossil locations, indicating that expansion and retreat occurred in the past (Waring et al., 1975). It is difficult to match all the details of paleogeological or paleoclimatic events to the ecological divergence observed for specific nodes, although our findings offer a quantitative interpretation with respect to the influence of climate on spruce speciation.

\subsection{Precipitation features tend to be the main driving factors of the primary divergence of spruce morphology}

The morphological tree in this study was based on spruce taxonomic schemes and highlights the divergence between leaf cross sections in spruce. Although this morphological tree is an artificial scheme, our results indicate that precipitation features were the primary trigger of the divergence between quadrangular leaves and flattened leaves among spruce species. A universal pattern was not observed for the climatic variables with respect to the ecological divergence of spruce morphology, which varied according to the specific nodes or splits.

The first split of the basal node of the morphological tree was based on the leaf cross section (i.e., quadrangular vs. flattened); however, each sister group is actually a combination of multiple traits, including the size, shape, color and pubescent or glabrous state of the seed cones, seed scales, bud scales, leaves, leaf apex, and first- and secondyear branchlets (Farjón, 1990; Sigurgeirsson and Szmidt, 1993; Fu et al., 1999). The morphological and morphometric traits of spruce species have been demonstrated to produce strong climatic signals; however, specific traits for different species do not necessarily exhibit the same response to specific environmental gradients (Wang et al., 2015; Li et al., 2016). This inconsistency in response is likely due to parallel evolution because morphological similarity among species does not necessarily coincide with the phylogenetic relatedness of species (Went, 1971; Orr, 2005). Accordingly, spruce species with similar morphological characteristics but distant phylogenetic relatedness may differ because of the tradeoff between niche conservatism and ecological divergence. In addition, the composition of traits within a species is also species specific. For example, the shape of the leaf cross section covaries along with the stomatal line position on the leaf surface, seed scale arrangement and seed scale texture. However, evidence in support of the coevolution between the leaf cross section (quadrangular, Q, vs. flattened, F) and seed scale arrangement (close, C, vs. loose, L) has not been observed. Trait combinations such as $\mathrm{Q}+\mathrm{C}, \mathrm{Q}+\mathrm{L}$, $\mathrm{F}+\mathrm{C}$ and $\mathrm{F}+\mathrm{L}$ are found in $22,2,4$ and 5 of the 33 species in Picea, respectively (Farjón, 2001). Therefore, without providing additional details, a universal pattern of ecological divergence cannot be predicted for the entire morphological tree of Picea.

\subsection{Divergence of morphology and phylogeny among spruce species is affected by different selective pressures under parallel evolution}

Closely related species in a phylogenetic tree tend to be similar in appearance, although this may not be so under parallel evolution (Hoekstra and Price, 2004; Baum et al., 2005; Orr, 2005), and both cases can be observed in spruce. First, of the three clades in the phylogenetic tree, most of the spruce species (19 of 22) in clade 1 and clade 2 tended to have quadrangular leaves, whereas nearly half of the spruce species (6 of 11) in clade 3 tended to have flattened leaves. In addition, two North American species, P. rubens and P. mariana, are sister species in both constructed trees. Accordingly, the morphological divergence and phylogenetic divergence of these species are subject to the same selective pressures. Second, cases of parallel evolution are quite obvious. For example, two Asian species, P. purpurea and P. wilsonii, are sister species in the phylogenetic tree but are located in different sections of the morphological tree; this scenario is also observed for two other North American species, P. glauca and $P$. engelmannii. As a result, the morphological and phylogenetic divergences for these species pairs are subject to different selective pressures, providing a test of our second 
hypothesis. This finding suggests that the divergence of morphology and phylogeny among the species in question may or may not be subject to different selective pressures depending on the process of speciation.

\subsection{Significance and implications of the findings of this research in relation to future climate change}

According to the 1997 UNPE standard climate zone classification (Middleton and Thomas, 1997), eight spruce species are in arid and semiarid areas, 11 in dry subhumid areas and 14 in humid areas. The scenario of global climate change predicts that there would be severe and widespread droughts over land areas within the next 30-90 years, resulting from decreased precipitation and/or increased evaporation, and significant increases in aridity have already occurred in many subtropical and adjacent humid regions (Dai, 2012; Greve and Seneviratne, 2015). When overlapping the spruce sampling points with the future aridity changes map (data not shown), nearly all the spruce species whose original distribution is in subhumid and humid areas would be subject to drought stress. Thus, our findings suggest that spruces with quadrangular leaves in clade 1 would be predicted to expand, while those with flattened leaves in clade 2 or clade 3 would be predicted to retreat. This should be taken into account in the context of strategizing in response to future climate change.

\section{Summary and conclusions}

In summary, the influence of climate on the divergence of the morphology and phylogeny of spruces is mediated by a number of biotic and abiotic factors, such as geographical isolation, niche conservatism and ecological adaptation. A major finding from this study is that temperature and precipitation parameters have tended to be the main driving factors for the primary divergence of spruce phylogeny and morphology, respectively. In addition, we observed an increasing magnitude in terms of ecological divergence among sister groups from the basal nodes (older) to the terminal nodes (younger) on an evolutionary timescale. Our hypotheses are therefore largely verified by the findings of the present study. However, exceptions to the overall pattern cannot be ignored. For example, although most spruce species with quadrangular leaves tend to occur in drier habitats, Taiwan spruce ( $P$. morrisonicola) presents quadrangular leaves and is naturally distributed in subtropical areas with abundant rainfall; thus, its present distribution is likely within a refugium from the postglacial period (Tsukada, 1966; Xu et al., 1980). Further work that considers all of the determinants is required to understand the forces driving ecological divergence among spruce sister groups or species. In addition, our findings shed light on the management issues with respect to spruce distribution under future climate change.
Data availability. The relevant data are presented in the paper and the Supplement.

\section{Information about the Supplement}

Additional supporting information may be found in the Supplement of this article:

Table S1 index of divergence $(D)$ from the phylogenybased SEEVA evaluation of spruce species worldwide.

Table S2 index of divergence $(D)$ from the morphologybased SEEVA evaluation of spruce species worldwide.

\section{The Supplement related to this article is available online at doi:10.5194/bg-14-2307-2017-supplement.}

Author contributions. Guo-Hong Wang conceived and designed the experiments. All authors performed the experiment. GuoHong Wang and $\mathrm{He} \mathrm{Li}$ analyzed and interpreted the data and wrote the paper.

Competing interests. The authors declare that they have no conflict of interest.

Acknowledgements. We thank Xing Bai, Lijiang Zhou, Miao Ma, Qinggui Wang, Hongchun Wang, Zhi Ma, Ziying Chen and Tiancai Chen for providing field assistance. This work was supported by the National Natural Science Foundation of China (41571045), the Chinese National Basic Research Program (2014CB954201) and the National Natural Science Foundation of China (30870398).

Edited by: T. Zha

Reviewed by: two anonymous referees

\section{References}

Bailey, S. F., Rodrigue, N., and Kassen, R.: The effect of selection environment on the probability of parallel evolution, Mol. Biol. Evol., 32, 1436-1448, doi:10.1093/molbev/msv033, 2015.

Baum, D. A. and Offner, S.: Phylogenies \& tree-thinking, Am. Biol. Teach., 70, 222-229, doi:10.1662/00027685(2008)70[222:PT]2.0.CO;2, 2008.

Baum, D. A., Smith, S. D., and Donovan, S. S.: Evolution. The tree-thinking challenge, Science, 310, 979-980, doi:10.1126/science.1117727, 2005.

Dai, A.: Increasing drought under global warming in observations and models, Nat. Clim. Chang., 3, 52-58, doi:10.1038/nclimate1633, 2012.

Darnell, R. M. and Dillon, L. S.: Ecology and the origin of species. Introductory statement, Am. Zool., 10, 7-8, 1970.

Escudero, M., Valcarcel, V., Vargas, P., and Luceno, M.: Significance of ecological vicariance and long-distance dispersal in the diversification of Carex sect. Spirostachyae (Cyperaceae), Am. J. Bot., 96, 2100-2114, doi:10.3732/ajb.0900134, 2009. 
Farjón, A.: Pinaceae: Drawings and Descriptions of the Genera Abies, Cedrus, Pseudolarix, Keteleeria, Nothotsuga, Tsuga, Cathaya, Pseudotsuga, Larix and Picea, Cambridge University Press, Konigstein, Germany, 1990.

Farjón, A.: World Checklist and Bibliography of Conifers, 2nd Edn., Cambridge University Press, Cambridge, UK, 2001.

Fisher, R. A.: Statistical Methods for Research Workers, 13th Edn., Hafner Press, Hafner, NY, 1958.

Fu, L., Li, N., and Mill, R. R.: Picea, in: Flora of China, edited by: Wu, Z.-Y. and Raven, P. H., Science Press, Beijing, China, 2532, 1999.

GBIF: Global Biodiversity Information Facility, available at: http: //www.gbif.org (last access: 3 May 2017), 2015.

Givnish, T. J.: Ecology of plant speciation, Taxon, 59, 1326-1366, 2010.

Greve, P. and Seneviratne, S. I.: Assessment of future changes in water availability and aridity, Geophys. Res. Lett., 42, 54935499, doi:10.1002/2015GL064127, 2015.

Hampe, A. and Petit, R. J.: Cryptic forest refugia on the 'Roof of the World', New Phytol., 185, 5-7, doi:10.1111/j.14698137.2009.03112.x, 2010.

Hewitt, G.: The genetic legacy of the Quaternary ice ages, Nature, 405, 907-913, doi:10.1038/35016000, 2000.

Hijmans, R. J., Cameron, S. E., Parra, J. L., Jones, P. G., and Jarvis, A.: Very high resolution interpolated climate surfaces for global land areas, Int. J. Climatol., 25, 1965-1978, doi:10.1002/joc.1276, 2005.

Hoekstra, H. E. and Price, T.: Parallel evolution is in the genes, Science, 303, 1779-1781, doi:10.1126/science.1096413, 2004.

Klymiuk, A. A. and Stockey, R. A.: A lower Cretaceous (Valanginian) seed cone provides the earliest fossil record for Picea (Pinaceae), Am. J. Bot., 99, 1069-1082, doi:10.3732/ajb.1100568, 2012.

LePage, B. A.: New species of Picea A. Dietrich (Pinaceae) from the middle Eocene of Axel Heiberg Island, Arctic Canada, Bot. J. Linn. Soc., 135, 137-167, doi:10.1111/j.10958339.2001.tb01088.x, 2001.

Li, H., Wang, G. H., Zhang, Y., and Zhang, W.: Morphometric traits capture the climatically driven species turnover of 10 spruce taxa across China, Ecol. Evol., 6, 1203-1213, doi:10.1002/ece3.1971, 2016.

Li, Y., Stocks, M., Hemmila, S., Kallman, T., Zhu, H., Zhou, Y., Chen, J., Liu, J., and Lascoux, M.: Demographic histories of four spruce (Picea) species of the Qinghai-Tibetan Plateau and neighboring areas inferred from multiple nuclear loci, Mol. Biol. Evol., 27, 1001-1014, doi:10.1093/molbev/msp301, 2010.

Liu, T.: A new proposal for the classification of the genus Picea, Acta Phytotaxonomica et Geobotanica, 33, 227-245, 1982.

Lockwood, J. D., Aleksic, J. M., Zou, J., Wang, J., Liu, J., and Renner, S. S.: A new phylogeny for the genus Picea from plastid, mitochondrial, and nuclear sequences, Mol. Phylogenet. Evol., 69, 717-727, doi:10.1016/j.ympev.2013.07.004, 2013.

López-Reyes, A., de la Rosa, J. P., Ortiz, E., and Gernandt, D. S.: Morphological, molecular, and ecological divergence in $\mathrm{Pi}-$ nus douglasiana and P. maximinoi, Syst. Bot., 40, 658-670, doi:10.1600/036364415X689384, 2015.

Luebert, F., Couvreur, T. L., Gottschling, M., Hilger, H. H., Miller, J. S., and Weigend, M.: Historical biogeography of Boraginales:
West Gondwanan vicariance followed by long-distance dispersal?, J. Biogeogr., 44, 158-169, doi:10.1111/jbi.12841, 2017.

Mayr, E.: Ecological factors in speciation, Evolution, 1, 263-288, doi:10.2307/2405327, 1947.

Middleton, N. and Thomas, D. S. G.: World Atlas of Desertification, 2nd Edn., Edward Arnold press, London, UK, 1997.

Münkemüller, T., Boucher, F. C., Thuiller, W., and Lavergne, S.: Phylogenetic niche conservatism-common pitfalls and ways forward, Funct. Ecol., 29, 627-639, doi:10.1111/1365-2435.12388, 2015.

Orr, H. A.: The probability of parallel evolution, Evolution, 59, 216-220, doi:10.1554/04-309, 2005.

Peterson, A. T., Soberón, J., and Sanchez-Cordero, V. V.: Conservatism of ecological niches in evolutionary time, Science, 285, 1265-1267, doi:10.1126/science.285.5431.1265, 1999.

Pyron, R. A., Costa, G. C., Patten, M. A., and Burbrink, F. T.: Phylogenetic niche conservatism and the evolutionary basis of ecological speciation, Biol. Rev., 90, 1248-1262, doi:10.1111/brv.12154, 2015.

Ran, J. H., Wei, X. X., and Wang, X. Q.: Molecular phylogeny and biogeography of Picea (Pinaceae): Implications for phylogeographical studies using cytoplasmic haplotypes, Mol. Phylogenet. Evol., 41, 405-419, doi:10.1016/j.ympev.2006.05.039, 2006.

Schemske, D. W.: Adaptation and the origin of species, Am. Nat., 176, 4-25, doi:10.1086/657060, 2010.

Schluter, D., Clifford, E. A., Nemethy, M., and McKinnon, J. S.: Parallel evolution and inheritance of quantitative traits, Am. Nat., 163, 9-22, doi:10.1086/383621, 2004.

Shi, N.: Development of spruce and fir in north China during the Pliocnen and the early Pleistonene: palaeoclimatic implications, Quaternary Sci., 16, 319-328, 1996 (in Chinese).

Sigurgeirsson, A. and Szmidt, A. E.: Phylogenetic and biogeographic implications of chloroplast DNA variation in Picea, Nord. J. Bot., 13, 233-246, doi:10.1111/j.17561051.1993.tb00043.x, 1993.

Spribille, T. and Chytry, M.: Vegetation surveys in the circumboreal coniferous forests: a review, Folia Geobot., 37, 365-382, doi:10.1007/Bf02803253, 2002.

Struwe, L., Smouse, P. E., Heiberg, E., Haag, S., and Lathrop, R. G.: Spatial evolutionary and ecological vicariance analysis (SEEVA), a novel approach to biogeography and speciation research, with an example from Brazilian Gentianaceae, J. Biogeogr., 38, 1841-1854, doi:10.1111/j.1365-2699.2011.02532.x, 2011.

Taylor, R. J.: Picea, in: Flora of North America north of Mexico, Vol. 2: Pteridophytes and gymnosperms, edited by: Flora of North America Editorial Committee, Oxford University Press, New York, NY, 369-373, 1993.

Tseng, Y. S.: Studies on the vegetation ecology of Salihsianhsi watershed in central Taiwan II: studies on the forest dynamics and population structure of Taiwan spruce forest, Master's Thesis, Institute of Forestry, National Taiwan University, Taipei, 1991.

Tsukada, M.: Late pleistocene vegetation and climate in taiwan (formosa), P. Natl. Acad. Sci. USA, 55, 543-548, 1966.

Walker, D.: Late Pleistocene early Holocene vegetational and climatic changes in Yunnan Province, southwest China, J. Biogeogr., 13, 477-486, doi:10.2307/2844968, 1986. 
Wang, G. H., Liu, J. L., and Meng, T. T.: Leaf trait variation captures climate differences but differs with species irrespective of functional group, J. Plant Ecol., 8, 61-69, doi:10.1093/jpe/rtu009, 2015.

Waring, R. H., Emmingham, W. H., and Running, S. W.: Environmental limits of an endemic spruce, Picea-breweriana, Can. J. Bot., 53, 1599-1613, 1975.

Webb, C. O., Ackerly, D. D., McPeek, M. A., and Donoghue, M. J.: Phylogenies and community ecology, Annu. Rev. Ecol. Syst., 33, 475-505, 2002.

Weber, M. G., Wagner, C. E., Best, R. J., Harmon, L. J., and Matthews, B.: Evolution in a community context: on integrating ecological interactions and macroevolution, Trends Ecol. Evol., 32, 291-304, doi:10.1016/j.tree.2017.01.003, 2017.

Went, F. W.: Parallel evolution, Taxon, 20, 197, doi:10.2307/1218877, 1971.

Wiens, J. J.: Speciation and ecology revisited: phylogenetic niche conservatism and the origin of species, Evolution, 58, 193-197, doi:10.1554/03-447, 2004.

Wiens, J. J. and Graham, C. H.: Niche conservatism: integrating evolution, ecology, and conservation biology, Annu. Rev. Ecol. Evol. S., 36, 519-539, doi:10.1146/annurev.ecolsys.36.102803.095431, 2005.
Wiley, E. O.: Vicariance biogeography, Annu. Rev. Ecol. Syst., 19, 513-542, doi:10.1146/annurev.es.19.110188.002501, 1988.

Wolf, P. G., Schneider, H., and Ranker, T. A.: Geographic distributions of homosporous ferns: does dispersal obscure evidence of vicariance?, J. Biogeogr., 28, 263-270, doi:10.1046/j.13652699.2001.00531.x, 2001.

Wu, Z., Wu, Z., Hu, D., Ye, P., and Zhou, C.: Geological evidences for the Tibetan Plateau uplifted in late Oligocene, Acta Geol. Sin.-Engl., 81, 577-587, 2007 (in Chinese).

Xu, R., Tao, J. R., and Sun, X. J.: On the discovery of a Quercus semicarpifolia Bedin Mount Shisha Pangma and its significance in botany and geology, J. Integr. Plant Biol., 15, 103-119, 1973 (in Chinese).

Xu, R., Kong, Z. C., and Du, N. Q.: Plant assemblages of Picea and Abies in the Pleistocene and implications for Quarternary study, Quaternary Sci., 5, 48-56, 1980 (in Chinese).

Yang, G. Z., Chen, Y. F., Zhao, W. C., Chen, X. Y., Wu, L. T., Zhao, G. R., and Lu, Z. F.: Plant Resource Investigation in Nantzuhsien Creek Watershed in Yushan of National Park, Yushan of National Park, Nantou, Taiwan, 2002 (in Chinese). 